\title{
Comparison of the Efficacy of Foley Catheter Balloon with Dinoprostone Gel for Cervical Ripening at Term
}

\author{
Krishna Dahiya", Kanika Malik, Archit Dahiya, Smiti Nanda \\ Department of Obstetrics and Gynecology, Pt.BDS, PGIMS, Rohtak \& MMIMSR, Mullana, Ambala, India. \\ Email: "krishnadahiya@rediffmail.com, drkrishnadahiya@gmail.com
}

Received July 25 ${ }^{\text {th }}$, 2012; revised August $29^{\text {th }}$, 2012; accepted September $4^{\text {th }}, 2012$

\begin{abstract}
Objective: The purpose of this study was to compare the efficacy of extra-amniotic Foley catheter with intra cervical Dinoprostone gel for preinduction cervical ripening. Study Design: A randomized, prospective study was conducted in the Department of Obstetrics and Gynecology, PGIMS Rohtak on 100 pregnant women admitted for induction of labor. Fifty patients were randomized to receive Dinoprostone gel and 50 patients to receive intracervical, extra-amniotic Foley catheter. Results: The two groups were comparable with respect to maternal age, parity, gestational age, indication for induction, and initial Bishop scores. Both groups had a significant change in Bishop score (4.18 \pm 1.81 and 4.6 \pm 1.48 respectively, $\mathrm{p}<0.001$ ); however, there was no significant difference between the groups. Mean duration of induction to delivery was $18.51 \pm 8.52$ in Foley catheter group and $18.21 \pm 11.13$ in prostaglandin group, the difference being statistically insignificant. Among 50 cases of prostaglandin only single dose was sufficient for $23(46 \%)$ cases to induce labor. But in 27 (54\%) cases 2nd dose of prostaglandin were required. The expenditure of intervention showed that Rs. 325 were required for induction by prostaglandin as compared to Rs. 60/- for Induction by Foley's catheter and the difference was highly significant statistically There was no difference between the groups in mode of delivery, infant weight, apgar score and intrapartum complications. Conclusion: In conclusion, although both Foley catheter and dinoprostone gel appear to be effective agents for cervical ripening. Foley catheter causes less fetal distress, cheap and safety profile of Foley catheter is such that it can be used on an out patient basis, but not dinoprostone gel. These results make Foley catheter comparable or even superior to dinoprostone gel for cervical ripening specially in developing countries.
\end{abstract}

Keywords: Foley Catheter; Dinoprostone Gel; Cervival Ripening

\section{Introduction}

The goal of obstetric is a pregnancy that results in a healthy infant and a healthy mother. For majority of women, labour starts spontaneously and results in vaginal delivery at or near term. Sometimes because of medical or obstetrics complications of pregnancy, cervical ripening and induction of labour is often required. Induction of labour is indicated when the benefits to either the mother or fetus outweigh those of continuing the pregnancy [1].

Common indications for labour induction include preeclampsia, premature rupture of membranes, chorio-amnionitis, intrauterine growth retardation, isoimmunisation, maternal medical problems, fetal demise, postdated pregnancy and oligohydramnios. The chief contraindications to labour induction are placenta praevia, transverse lie, prolapsed umbilical cord, scarred uterus, active genital herpes infection, and pelvic structural deformities. Induc-

${ }^{*}$ Corresponding author. tion of labour is common in obstetric practice. Induction of labour should be simple, safe, effective and preferably non-invasive. The success of induction depends to a large extent on the consistency, compliance and configuration of the cervix [2]. The unripe cervix thus remains a well recognized impedent to the successful induction of labour [3].

Therefore, cervical ripening or preparedness for induction should be assessed before a regimen is selected. Many methods have been devised to ripen the cervix and this process has been described as preinduction cervical ripening. Pharmacologic agents available for cervical ripening and labour induction include prostaglandins, misoprostol, mifepristone and relaxin.

Local application of Prostaglandin $\mathrm{E}_{2}$ ( $\mathrm{PGE}_{2}$ or Dinoprostone) has been in use for cervical ripening since late 1960s. PGE ${ }_{2}$ administered intravaginally or intracervically, improves Bishop Score and induction to delivery time when compared to those of untreated controls. The local application of $\mathrm{PGE}_{2}$ results in direct softening of 
the cervix by a number of different mechanisms [4,5]. Uterine tachysystole and accompanying fetal distress is reported following administration of $\mathrm{PGE}_{2}$ in 1 to 5 percent of women [6].

The use of a cervical catheter also appears to be effective for cervical ripening $\&$ has been shown to shorten induction to delivery interval, decrease caesarean section rate and increase the rate of spontaneous vaginal delivery [7].

Different catheter ballon volumes ranging from 30 - 80 $\mathrm{ml}$. and even double balloon catheter have been studied for cervical ripening [8]. The mechanical action of the Foley catheter strips the fetal membranes from the lower uterine segment and causes rupture of lysosomes in the decidual cells, part of which is phospholipase A. These lytic enzymes act on phospholipase to form arachidonic acid which is converted to prostaglandin, thereby improving the consistency and effacement of the cervix $[9,10]$. The advantage of this method over the pharmacological preparation includes simplicity of preservation, lower cost and reduction of side effects. This study was planned to compare the efficacy and safety of $50 \mathrm{ml}$. Intracervical Foley catheter balloon with that of Dinoprostone gel for cervical ripening before induction of labour at term.

\section{Material and Methods}

This prospective randomised study was conducted in the Department of Obstetrics and Gynaecology, Pt. B.D. Sharma PGIMS, Rohtak. One hundred pregnant women admitted in the labour ward for induction of labour were selected for the study. Alternate woman were assigned into study group and control group.

Those in Group 1 were administered intracervical extra-amniotic Foley catheter balloon inflated with $50 \mathrm{ml}$ of normal saline. While those of Group 2 received intracervical dinoprostone gel.

Inclusion criteria included all patients with $37-41$ weeks of gestation with reactive fetal heart rate, Singleton pregnancy, vertex presentation, Unfavorable cervix (modified Bishop score $<6$ ) and Intact membranes. Excluded were those patients with multiple pregnancies, Malpresentation, Placenta praevia and Scarred uterus.

Detailed history, general physical, systemic and obstetric examination including per vaginum examination for assessment of Bishop Score were carried out. Patients were subjected to investigations like hemoglobin, complete urine examination, blood grouping, standard test for syphilis (STS), HIV and ultrasonography. A written informed consent was taken before the procedure.

Under all aseptic precautions, Foley catheter No. 16F was inserted extra-amniotically in woman selected for study group. The balloon of this catheter was inflated with $50 \mathrm{ml}$ normal saline and Foley catheter pulled so that the bulb rests on the internal os. The catheter was stripped to the thigh and was removed after 12 hours or earlier if membranes ruptured.

While in control group dinoprostone gel i.e. $0.5 \mathrm{mg}$ in $3 \mathrm{gm}$ base was introduced. Patient was re-assessed after 6 hours and if there was no improvement in Bishop Score, patient was subjected to another dose of dinoprostone gel.

Oxytocin augmentation was started if Bishop's score was more than 6 . Women with no improvement in Bishop's score at the end of 24 hours were considered as failure. Partogram was maintained during labour.

The primary outcome variable was a change in Bishop Score. The secondary outcome was the need for oxytocin augmentation, induction-delivery interval, mode of delivery, maternal complications \& neonatal outcome and the results were analysed statistically by Student's t test, Chi square test and Mann Whitney test. Differences with a $p$ value of $<0.05$ were considered statistically significant with the confidence limit of $95 \%$ (power of test $80 \%)$.

\section{Result}

Among the 100 patients, 50 patients were selected for induction by Foley catheter and 50 patients were induced by prostaglandin gel. The mean age of the patients was $24.92 \pm 3.84$ years in Group 1 and $24.62 \pm 3.31$ years in Group 2 (Table 1). Mean gestational age in weeks were similar between the two groups, i.e. $39.62 \pm 2.37$ and $39.52 \pm 1.26$ in Group 1 and Group 2 respectively (p = $0.935)$. The two groups were comparable with respect to maternal age, parity, gestational age, indication for induction, and initial Bishop scores.

Table 2 shows the mean change in Bishop Score after 12 hours of initiation of process. In Group 1, mean change in Bishop Score was $4.18 \pm 1.81$ as compared to $4.6 \pm 1.48$ in Group 2, however no significant difference between the mean changes in the two groups could be established.

Induction to delivery interval was similar in both groups as $18.51 \pm 8.52$ hours in Foley catheter group and $18.21 \pm 11.13$ hours in the prostaglandin gel group (Table 3). In the prostaglandin gel group, 27 (57\%) patients required repeat dose with the average patient requiring 1.5 applications. No Foley catheter needed to be replaced after the initial application.

Oxytocin was started when Bishop score was more than 6 or earlier if the patient had spontaneous rupture of membranes. A total of $11(22 \%)$ and 18 (36\%) women in Groups 1 and 2, respectively, did not receive any oxytocin supplementation. In Group 1, 42 (84\%) women delivered vaginally spontaneously as compared to 38 (76\%) in 
Table 1. Patient characteristics.

\begin{tabular}{lcc}
\hline & \multicolumn{1}{c}{ Patient profile } \\
\hline & Foley group ( $\mathrm{n}=50) \mathrm{N}(\%)$ & Prostaglandin group (n= 50) N (\%) \\
\cline { 2 - 3 } Age (yrs.) (mean \pm SD) & $24.92 \pm 3.84$ & $24.62 \pm 3.31$ \\
Gravida & $31(62 \%)$ & $28(56 \%)$ \\
$\quad$ Primigravida & $19(38 \%)$ & $22(44 \%)$ \\
$\quad$ Multigravida & $39.62 \pm 2.37$ & $39.52 \pm 1.26$ \\
Gestation age (in weeks) & & $3.04 \pm 1.19$ \\
Inean \pm SD) & $2.98 \pm 1.39$ & \\
Indical Bishop score & & $28(56 \%)$ \\
$\quad$ Postdation for induction & $13(26 \%)$ & $16(32 \%)$ \\
Pregnancy induced & $30(60 \%)$ & $6(12 \%)$ \\
$\quad$ Hypertension & & \\
$\quad$ Rh-ve & $7(14 \%)$ & \\
\hline
\end{tabular}

Table 2. Change in bishop score (Mann-Whitney Test).

\begin{tabular}{ccccc}
\hline \multicolumn{5}{c}{ Ranks } \\
\hline Group & $\mathrm{N}$ & Mean rank & Sum of ranks \\
\hline \multirow{3}{*}{ Foley 1 Dianoprostol } & 2 & 50 & 44.32 & 2216.00 \\
& Total & 100 & 56.68 & 2834.00 \\
\hline
\end{tabular}

\begin{tabular}{cc}
\hline \multicolumn{2}{c}{ Test statistics $^{\mathbf{a}}$} \\
\hline \multicolumn{2}{c}{ Foley } \\
\hline Mann-Whitney U & 941.000 \\
Wilcoxon W & 2216.000 \\
Z & -2.172 \\
Asymp. Sig. (2-tailed) & 0.030 \\
\hline
\end{tabular}

${ }^{\mathrm{a}}$ Grouping variable: group.

Group 2 ( $\mathrm{p}>0.05$ ). Delivery data showed no significant difference between the two groups with respect to spontaneous or operative delivery.

There were few maternal side effects in the either groups. Discomfort on the placement of the Foley catheter was found in 4 (8\%) of patients as compared to $3(6 \%)$ in case of prostaglandin gel group. However, hyperactivity of uterus and no reassuring fetal heart rate pattern was observed in the prostaglandin gel group the difference being statistically significant.

Fetal outcome data showed no significant difference between the Foley catheter and the prostaglandin gel groups with respect to birth weight, 1-minute apgar scores and 5-minute Apgar scores (Table 3).

\section{Discussion}

The results of this study confirm that both prostaglandin gel and an intracervical Foley catheter are effective methods for preinduction cervical ripening. However, a comparison between the groups revealed that one method did not confer a statistically significant advantage over the other.

Prostaglandins are currently the most commonly used agents for the ripening of unfavourable cervix and for induction of labour. These pharmacologic agents are however unstable and may have less potency if they are not stored properly and their effects are not readily reversible. They are associated with problems such as variable absorption, unpredictable patient response, vomiting, diarrhoea, tachycardia, bronchospasm and infection [11].

In the present study there was no significant difference between Foley catheter balloon and locally applied prostaglandin in LSCS delivery rates (10\% vs $18 \%)$. Foley catheter balloon had a significantly higher rate of oxytocin induction and augmentation during labour. Cervical prostaglandin $E_{2}$ was less effective and has a significantly higher risk of excessive uterine activity and meconium staining.

The need for oxytocin augmentation was 39 (78\%) in group 1 and 32 (68\%) in group 2 in agreement with other studies [12-14]. Foley catheter is as effective as vaginal prostaglandin in enhancement of inducibility, with similar induction to delivery intervals and outcomes of labour.

Ezimokhai and Nwabinelli [12] found that ripening effect of a Foley catheter on the cervix in 21 primigravida to be similar to that of $5 \mathrm{mg}$ of PGE2 in vaginal gel in 14 primigravida. No complication was attributable to the use of either method but the Foley catheter was considered advantageous in its ease of use, economical and ready availability. St. Onge et al. [13] has compared the Foley catheter with a prostaglandin gel found both to be effective in changing the Bishop score, but neither found the Foley catheter to be more effective than gel. 
Table 3. Outcomes of preinduction cervical ripening in two groups.

\begin{tabular}{cccc}
\hline Characteristics & Foley group N (\%) & Prostaglandin group N (\%) & Statistical significance \\
\hline Induction to delivery interval (hours) & $18.51 \pm 8.52$ & $18.21 \pm 11.13$ & NS \\
Oxytocin augmentation & $39(78)$ & $32(64)$ & NS \\
Number of doses required & 0 & $27(54 \%)$ & $\mathrm{S}$ \\
Mode of delivery & & & NS \\
Spontaneous vaginal deliveries & $42(84)$ & $38(76)$ & NS \\
Assisted vaginal deliveries & $3(6)$ & $3(6)$ & NS \\
LSCS & $5(10)$ & $9(18)$ & NS \\
Patient discomfort & $4(8 \%)$ & $3(6 \%)$ & $\mathrm{S}$ \\
Hyperactivity of uterus & 0 & $4(8 \%)$ & $\mathrm{S}$ \\
FHR abnormality & $1(2 \%)$ & $6(12 \%)$ & NS \\
Birth weight (kg) & $2.95 \pm 0.385$ & $2.81 \pm 0.470$ & NS \\
Apgar score at 1 min & $6.74 \pm 0.664$ & $6.66 \pm 0.894$ & NS \\
Apgar score at 5 min & $8.7 \pm 0.543$ & $8.48 \pm 0.677$ &
\end{tabular}

A clinical study by Rashid et al. [14] found favourable and beneficial effect of Foley catheter. Vaknin et al. [15] performed a meta-analysis comparing the efficacy and safety of cervical ripening and labour induction by Foley catheter balloon versus locally applied prostaglandin in third trimester of pregnancy.

Comparing the costs of Foley catheter and prostaglandin gel, the cost of cervical ripening by prostaglandin is almost 5 times more in comparison to Foley catheter and cost becomes more because many patients required more than a single dose.

As more patients are induced for post-datism and other indications, the question of the best method of pre-induction cervical ripening remains controversial. The current study supports both the Foley catheter and the use of exogenous prostaglandins as effective and safe. However in specific patient populations, such as those with vaginal births after Caesarean section, the use of a Foley catheter is a safer option. No common side effects (intrapartum or postpartum fever and vaginal bleeding, the quite-rare rupture of membranes, along with displacement of the presenting part and umbilical cord prolapse) have been seen with this simplified insertion technique in this study.

Moreover dinoprostone gel can not be used in patients with medical disorders like bronchial asthma, epilepsy and glaucoma in which Foley catheter can be used safely for cervical ripening. However, dinoprostone gel use is associated with higher incidence of fetal distress and hence increased chances of abdominal delivery. Therefore considering the side effects of dinoprostone gel, its irreversible effect on uterine contraction, cost (Foley Rs. 60 vs $\mathrm{PGE}_{2}$ Rs. 217) and requirement of proper monitoring of foetus and mother, it is better to use Foley catheter than dinoprostone gel. It avoids the need for continuous monitoring in ripening phase in health care facility. Hence, Foley catheter is safe in contrast to dinoprostone gel.

This present study showed that both Foley catheter and dinoprostone gel appeared to be effective agents for cervical ripening and labour induction. There is no significant difference in ripening efficacy, mode of delivery or perinatal outcome. Foley catheter causes less fetal distress and safety profile of Foley catheter is such that it can be used on an out patient basis, but not dinoprostone gel. These results make Foley catheter comparable or even superior to dinoprostone gel for cervical ripening specially in developing countries. Thus it is concluded that cervical ripening with extra amniotic catheter balloon has the advantage of simplicity, low cost, reversibility and lack of serious side effects. 


\section{REFERENCES}

[1] B. A. Brindley and R. J. Sokol, "Induction and Augmentation of Labor. Basis and Methods for Current Practice," Obstetrical \& Gynecological Survey, Vol. 43, No. 12, 1988, pp. 730-743.

doi:10.1097/00006254-198812000-00004

[2] K. F. Trofatter, “Cervical Ripening," Clinical Obstetrics abd Gynecology, Vol. 35, No. 3, 1992, pp. 476-486. doi:10.1097/00003081-199209000-00007

[3] J. E. Stempel, R. P. Prins and S. Dean, "Preinduction Cervical Ripening: A Randomized Prospective Comparison of the Efficacy and Safety of Intravaginal and Intracervical Prostaglandin $E_{2}$ Gel," American Journal of Obstetrics \& Gynecology, Vol. 176, No. 6, 1997, pp. 1305-1312. doi:10.1016/S0002-9378(97)70350-8

[4] N. Uldbjerg, G. Ekman and A. Malmstrom, "Ripening of the Human Uterine Cervix Related to Changes in Glycosaminoglycans and Collagenolytic Activity," American Journal of Obstetrics \& Gynecology, Vol. 147, No. 6, 1983, pp. 662-666.

[5] K. F. Trofatter, D. Bowers, R. N. Standby, A. Gall and A. P. Killam, "Preinduction Cervical Ripening with Prostaglandin $E_{2}$ Gel," American Journal of Obstetrics \& Gynecology, Vol. 153, No. 3, 1985, pp. 268-271.

[6] R. P. Prins, R. N. Bolton and C. Mark, "Cervical Ripening with Intravaginal Prostaglandin $\mathrm{E}_{2}$ Gel,” Obstetrics \& Gynecology, Vol. 63, 1984, pp. 697-702.

[7] C. James, A. Peedicayil and L. Seshardi, "Use of the Foley Catheter as a Cervical Ripening Agent Prior to Induction of Labor," International Journal of Gynecology \& Obstetrics, Vol. 47, No. 3, 1994, pp. 229-232. doi:10.1016/0020-7292(94)90566-5

[8] D. A. Guinn, A. R. Goepfert, M. Christine, J. Owen and J. C. Hauth, "Extra-Amniotic Saline, Infusion and Intracervical Dinoprostone Gel for Cervical Ripening,” Obstet- rics \& Gynecology, Vol. 182, 2000, pp. 1039-1044.

[9] D. J. Sherman, E. Frenkel, J. Tovbin, S. Arieli, E. Caspi and I. Bukovsky, "Ripening of the Unfavorable Cervix with Extra-Amniotic Catheter Balloon: Clinical Experience and Review,” Obstetrical \& Gynecological Survey, Vol. 51, No. 10, 1996, pp. 621-627. doi:10.1097/00006254-199610000-00022

[10] F. Arias, "Pharmacology of Oxytocin and Prostaglandins,” Clinical Obstetrics and Gynecology, Vol. 43, No. 3, 2000, pp. 455-468. doi:10.1097/00003081-200009000-00006

[11] S. K. Sandhu and R. Tung, "Use of Foley's Catheter to Improve the Cervical Score Prior to Induction of Labour," Journal of Obstetrics \& Gynaecology, Vol. 34, 1984, pp. 669-672.

[12] M. Ezimokhai and J. N. Nwabinelli, “The Use of Foley’s Catheter in Ripening the Unfavourable Cervix Prior to Induction of Labour," British Journal of Obstetrics and Gynaecology, Vol. 87, No. 4, 1980, pp. 281-286.

[13] R. D. St. Onge and G. T. Connors, "Preinduction Cervical Ripening: A Comparison of Intracervical Prostaglandin $\mathrm{E}_{2}$ Gel versus the Foley Catheter," American Journal of Obstetrics \& Gynecology, Vol. 172, No. 2, 1995, pp. 687690. doi:10.1016/0002-9378(95)90594-4

[14] M. Rashid, A. Begum, S. B. Chowdhury and S. Chowdhury, "Induction of Labor by Foley's Catheter Method. A Clinical Study of Forty Cases," Bangladesh Journal of Obstetrics \& Gynaecology, Vol. 9, No. 1, 1994, pp. 1621.

[15] Z. Vaknin, Y. Kurzweil and D. Sherman, "Foley Catheter Balloon vs Locally Applied Prostaglandins for Cervical Ripening and Labour Induction: A Systematic Review and Metaanalysis," American Journal of Obstetrics \& Gynecology, Vol. 203, No. 5, 2010, pp. 418-429. doi:10.1016/j.ajog.2010.04.038 